\section{Surfing the Waves of Infodemics: Building a Cohesive Philippine Framework against Misinformation}

\section{DOI: 10.52629/jamsa.v9i1.251}

Background The exponential increase in information accompanying COVID-19 has presented significant barriers to effective health communication. In a country with 76 million active social media accounts, this infodemic due to the pandemic has exposed inadequacies in the Philippine information systems.

Purpose of the Study As such, this paper aims to present the infodemic in the Philippine context, analyze existing frameworks countering misinformation, identify problems, and propose solutions for misinformation.

Methods A comprehensive review of existing policies was conducted by inputting keywords in known databases, and analyzing literature, laws, and social media policies in the Philippines.

Main Findings The analysis has shown that (1) the current non centralized system presents difficulties in mobilizing experts; (2) the older demographic is a neglected population amid high risk for misinformation; (3) individual passivity in searching for legitimate sources puts people at higher risk; (4) current legal frameworks insufficiently characterize and delineate misinformation and disinformation, leading to concerns on implementation and human rights. To address this, evidence recommends (1) creating a centralized government institution, representative of various sectors, to serve as the source of understandable and reliable scientific information; (2) strengthening current legal frameworks, with an emphasis on education, due process, and human rights; (3) ingraining a culture of fact-checking within the Filipino psyche via stakeholder engagement.
Joseph Rem Dela Cruz, Christl Jan S Tiu', Raphael Ian B Velasco', Hannah Joyce $Y$ Abella', Mark Vincent P Dela Cruz', Jemil Austin M Lacson', Ian Oliver D Macatangay', Erika P Ong', Jaypee M Paguntalan', Nanette B Doroja'

'University of Indonesia, Indonesia

Correspondence to: Joseph Rem Dela Cruz College of Medicine, University of the Philippines Manila

jcdelacruz13@up.edu.ph 
Principal Conclusion Clear roles and responsibilities, along with active stakeholder engagement, are needed to build individual resilience against misinformation and strengthen veritable institutions that aid the country in responding to future health crises.

Keywords Health Communication, Infodemics, Misinformation, Policy, Philippines 


\section{Background}

Public health communication plays a special role during a pandemic, particularly in facilitating public understanding of health, broadening health information sources, and influencing policy.1-3 In our efforts to address the COVID-19 pandemic, the crippling effect of infodemics can be felt as well. Infodemics are defined as the sudden or exponential increase of information in a short period of time, which encompasses both credible and unsourced, news (i.e., fake news) conveyed by institutions like the media and academe. ${ }^{4,5}$ This phenomenon has now become a critical roadblock in achieving public compliance to health measures. ${ }^{5}$

The Philippines has approximately 89 million social media users - equivalent to $80.7 \%$ of the total population. ${ }^{6}$ Considering that almost eleven hours per day is spent on the internet ${ }^{6}$, the average Filipino can access a mix of information and engage through any device. For example, most Filipinos access Facebook as a means of involvement in public affairs. ${ }^{7}$ By virtue of a prepaid subscription, approximately 95\% of the Philippines' 129.4 million mobile subscriptions are allowed access to Facebook's free version via the Free Basics app even without a registered Facebook account. ${ }^{8}$ In this setting, only headlines and captions of photos and videos are visible and allows for the propagation of clickbait and misleading headlines. ${ }^{8}$ Through exposure to these media, compounded with a low level of health literacy 9-14, Filipinos are susceptible to misinformation and disinformation regarding health measures. By definition, misinformation is the creation and dissemination of misleading information without manipulative intent while disinformation is more deliberate with malicious intent. 15,16

Ubiquitous misinformation and disinformation can cause cynicism, distrust, and fear in the general public. ${ }^{17-19}$ More importantly, effects of the infodemic on health are evident during the pandemic as Filipinos may subscribe to varying practices mistaken to be preventive, or worse, curative as false information circulate online..$^{20-25}$ For instance, the president publicly communicated and insisted on the legitimacy of using gasoline as an alternative disinfectant if alcohol is not available 26 - a clear concern especially when people abide by his advice. Information available in the internet can be leveraged for various interests regardless of truthfulness by utilizing emotional content that Filipinos are known to engage with ${ }^{27,28}$ while capitalizing on their digital literacy (or lack thereof). ${ }^{29,30}$ In addition, stoking culturallyspecific sentiments ${ }^{8}$ rooted in history, communitarian mindset ${ }^{31}$, and a value system based on discipline and conformity $^{32}$ can be used to enhance the spread of misinformation and disinformation alike.

While disinformation is undoubtedly an important problem, it will require a different approach and solution. For this paper, only misinformation will be discussed. Fact-checking and other regulatory mechanisms for 
misinformation and social media ${ }^{33}$ (e.g., civic society such as the Church, advocates, and the media) have existed before COVID-19. ${ }^{8}$ Despite these efforts, the pandemic has revealed inefficiencies, and misinformation such as cheap fakes (i.e., poorly constructed imitations of official announcements), and real data put out of context, otherwise known as misinformation, remain prevalent in social networks. 8,21,22,34 Through this paper, we aim to propose pragmatic solutions against misinformation in the Philippines.

\section{Objectives}

Specifically, this paper aims to:

1. Define and contextualize infodemics in the Philippines during the COVID-19 pandemic;

2. Assess current mechanisms in regulating misinformation in the Philippine media and government agencies;

3. Identify problems in the frameworks of these countermisinformation mechanisms; and

4. Propose policy revisions and pragmatic solutions to misinformation.

\section{Methods}

A comprehensive review of existing policies and mechanisms in Philippine social media and government arms in their combat against misinformation during the COVID-19 pandemic is made. Such policies and mechanisms range from implemented legislation that penalizes misinformation to fact-checking mechanisms of certain media. The problems and solutions are identified and proposed based on current literature by the World Health Organization (WHO) and other relevant sources. ${ }^{5,35,36}$ These were searched using PubMed and Google Scholar using words such as "infodemic", "COVID-19", "management", "Philippines", and the like.

\section{Problems identified on the mechanisms against misinformation in the Philippines}

According to an executive order (EO) issued by former President Benigno Aquino III, one of the original functions of the Inter-Agency Task Force on Emerging Infectious Diseases (IATF-EID) is to educate and alleviate public concerns on current health crises. ${ }^{14}$ However, there are no provisions on the implementing rules and regulations (IRR) of this policy.

Not much has changed since the issuance of the EO in 2014. There have since been no additional provisions to the IRR implemented to counteract the Philippines' lack of centralized top-down flow of information. The lack of IRR provisions addressing the paucity of necessary and correct information has caused much of the Filipino population to rely on informal or unsolicited information campaigns from private organizations or individuals ${ }^{36}$ There has been poor 
mobilization of key information and experts on critical areas due to lack of regulation of the content as well as the method of dissemination. Although opportunities towards institutionalizing unified discussions have been opened, these remain under the radar of public consciousness due to lack of government support and public policy.

Certain populations are more vulnerable to misinformation in social media. The older generation seems to be less critical of posts found on social media. ${ }^{15}$ In Facebook alone, it was shown that older age groups had a higher prevalence in sharing fake news compared to the previous younger age group - with the oldest population seven times more susceptible to sharing fake news compared to the youngest age groups. ${ }^{16}$ This signals a clear need for further development in media literacy interventions for this vulnerable population. ${ }^{15}$ While the $\mathrm{K}-12$ program has integrated media and information literacy into the school-aged population's curriculum, to the best of our knowledge, there were no similarly publicized programs in the Philippines required for adults. Having mentioned this, published evaluation of such programs should continually be implemented to ensure the effectiveness of such measures.

Being platforms for potential misinformation, social media networks are working towards limiting misinformation against COVID-19. For instance, Facebook has partnered with several institutions to fact-check COVID-19-related information. ${ }^{17}$ Once reviewed and tagged as false, these posts will be removed, reduced, or tagged with warning labels. Users who interacted with such information will see a post in their newsfeed linking to a WHO website for documenting and debunking false information. ${ }^{17}$ Further, fact-checked and legitimate articles are given space in the COVID-19 information center accessible at the sidebar of the Facebook website. ${ }^{17}$ Though these efforts are starting steps, these measures remain passive - in that, a user must be motivated to click and read through posts in the websites or pages to get the right information. Active engagement in searching for legitimate sources is needed or else people remain vulnerable to misinformation. ${ }^{11,18}$ People must also break free from echo chambers where their biases are magnified. ${ }^{19}$ Further, misinformation spread through person-toperson messaging may not be screened as this may violate the user privacy. Instead, limits on spamming and tracking suspicious spikes in messaging activity have been implemented. ${ }^{3}$

Several local policies may act as regulatory mechanisms for battling misinformation on social media in the Philippines. However, specific policies on misinformation in social media remain absent. There are no provisions regarding health misinformation in the Cybercrime Prevention Act of 2012. For most policies in place, clarity of scope, consistency of implementation, and lack of rehabilitative functions remain a challenge. ${ }^{21}$

The Republic Act (RA) No. 11469, known as the Bayanihan Heal as One Act, issued on 
March 2020 and implemented until June 2020, imposed sanctions for "spreading false information regarding the COVID-19 crisis on social media and other platforms" granting authority to the anti-cybercrime group of the Philippine National Police to implement penalties. ${ }^{22}$ However, consistency of implementation remained a struggle due to the limitation in the effectiveness of the law as well as the absence of clear implementing rules and regulations. Numerous instances of misinformation by individuals, public personalities, and officials have been cited in the news - varying from spreading doubt on the utility of face masks to the promotion of steam inhalation. $23,24,25,26,27,28$ These have remained uninvestigated or unpunished. Without clear provisions on the implementing rules and regulations, human rights and social media advocates stated that the law can be easily abused by those in power to file complaints against individuals, including journalists. ${ }^{29}$

In February 2020 and April 2020, criminal charges under Article 154 of the Revised Penal Code (RA 3815) were filed against individuals spreading fake information on COVID-19 - noting the public disorder that misinformation may cause. ${ }^{30}$ However, this law may not cover misinformation that is less likely to endanger public order - for example, false information on the use of gasoline to clean masks ${ }^{31}$ - despite its harmful effects on health. Local Government Units (LGUs) have also tried to contribute to the regulation of misinformation. For instance, in General Mariano Alvarez in Cavite, spreading false news is sanctioned: 6 months in prison or a penalty of 2,500 pesos..$^{32}$ However, efforts remain fragmented.

\section{Proposed Solutions}

In order to create a more sustainable information system that can address future health crises, a three-pronged plan involving various stakeholders and integrating evidence-based approaches with a focus on equity is proposed.

First, the Philippine government should institutionalize an intersectoral scientific body that consolidates relevant scientific data relating to an identified potential or actual problem. This may involve already existing agencies like the Departments of Science and Technology, and Health, among others. The main function of this integrated body is to serve as the single most central source of scientific information for the Filipino people. This body must be mandated to include appointees involving different sectors (e.g., health, social sciences, education, transportation, agriculture, economics, etc.) with relevant knowledge, expertise, and skills related to an identified problem. Such appointees must be properly screened and selected by means of their credentials and experience in a particular field. Their appointment must be approved by an independent body, preferably the duly recognized organization of experts in the field.

As such, the body must gather, synthesize, and contextualize relevant information via an intersectoral approach and ensure proper information dissemination down to 
the community level. In order to ensure this, they must verify the gathered data, convene media representatives before releasing relevant scientific information, coordinate with local government units (LGUs) regarding dissemination and implementation, and act as fact-checkers via public direct communication channels (e.g., Frequently Asked Questions or FAQ pages, social media messaging, chatbots, etc.). This synthesized knowledge will also serve as a basis for policy development and continuous evaluation.

The scientific body will also act as a central advisory body and consolidate formal and informal advice provided by existing advisory bodies as well as ad hoc task forces and technical working groups; whereby policy developers and implementers are required to heed this central advisory body; and the gathering of scientific advice will not be limited to emergencies, but will include prospectively evaluating anticipated problems.

Secondly, the Philippines must strengthen existing legal frameworks to clearly delineate misinformation from disinformation. The RA 3815 (Revised Penal Code) and RA 10175 (Cybercrime Law) must be amended to include clear definitions, or a separate act passed to cover recent developments. Specifically, misinformation penalties must be focused on informing the individual. This is achieved by applying tests on social media etiquette in the application of new accounts to social media sites; implementing a three-strike warning system for offenders, with account suspension and/or community service as the final penalty; and requiring repeat offenders to attend social media literacy seminars to reactivate their account. Meanwhile, disinformation must be properly defined as a crime punishable by the law, with a priority placed on human rights and due process. All solutions outlined here can also be put into legislation to provide durability even with successive political regime change.

Lastly, a culture of fact-checking in the Philippines must be enhanced by affirming the responsibility of social media companies as platforms for proper communication and information dissemination. There must be a strong mandate for the government to set standards for operation and ensure that a percentage of their profits be allocated to tracking down and analyzing misinformation. In addition, grassroots initiatives must be supported financially. Technical developments in their algorithms must also be prioritized. Changes to algorithms and the interface of social media platforms may also encourage a better environment for discourse on pressing issues. Aside from these, the government must also partner with social media companies to submit quarterly reports and share information on current online trends (e.g. location, velocity of change, the volume of traffic, public sentiment, etc.). All this information must be made transparent and publicly archived as per the Freedom of Information Act (Executive Order \#2, 2016). This can be used as a form of active 
evaluation of programs during emergency response. The government can also partner with social media influencers, community leaders, and even LGUs in charge of health and disaster management as local disseminators of information.

Journalistic outlets and social media companies must also ensure that they have a dedicated team to track down, verify, and correct misinformation online which is funded transparently, with conflicts of interest publicly cited. Proper socio-legal protections must be afforded to journalists in this line of work. Due protections are needed to ensure that individuals practice their work without fear of coercion or force. Meanwhile, media outlets, their editors, and contributors must abide by their code of ethics, produce objective content, and contextualize their live reports of current events and headlines to avoid clickbait culture.

Information asymmetry must be reduced to engage individuals to fact-check their own messaging and that of their peers. This is achieved through the seminars and information campaigns hosted by media outlets and the academe. Academics must also be informed of recent developments in research, publication, and communicating with wider audiences, policy makers, and the media via seminars, training, and integration in the health sciences curriculum. They must take a more proactive role in communicating science using methods more palatable to the public. All this, in addition to their role as analyzers of online behavior and the Filipino psyche. As such, topics on online trends in the social and behavioral sciences must be urgently prioritized, funded, and made easily accessible through existing mechanisms.

\section{Limitations of the study}

With the community quarantine implemented during the writing of this paper, the authors were unable to obtain literature that were unavailable online. As such, it is possible that existing research specific for Filipinos available in academic institutions and other relevant agencies was not considered. With that said, the references used in this paper include only reports published online and were sometimes from abroad. All articles reviewed were also in English. However, to be able to design better solutions, more studies should be made to understand this issue specifically in the local context. The Philippines has social dynamics and political systems shaped by years of history different from Western countries, where most studies on misinformation and disinformation are conducted.56 Therefore, while studies done in other countries are important, the recommendations they yield may not be effective in the local context, ${ }^{33}$ where social, economic, and political conditions are different.

Proposal of solutions in the form of a policy requires the thoughtful deliberation of several factors. The Hall model ${ }^{57,58}$ lists legitimacy, feasibility, and support as important aspects to consider in agenda 
setting. The authors were able to present relevant information regarding legitimacy and support such as recognized governing bodies and policies observed by the public. However, the issue of feasibility in implementing such a complex framework has not been evaluated. Though the authors considered existing literature in formulating the proposed solutions, consultation with experts may have been a helpful preliminary assessment for this aspect. Furthermore, future pilot testing or feasibility studies may be used to investigate the potential effects and resource requirements of the threepronged plan

\section{Recommendations}

It is worth noting that the proposed solutions could be exceedingly impactful especially at grassroots levels - if each individual is aware and fully understands their rights and roles in this system. At the same time, consultations with different stakeholders are necessary to uphold or establish formal partnerships as this is essential for the success of the interventions. The experts designated in the institutionalized intersectoral science body should also have clear and unique roles without compromising the ability to consolidate and produce integrated scientific information. Identification of roles and their extent should also be clear to other stakeholders such as media outlets, especially at a time of emergency. Moreover, current legal frameworks such as the Revised Penal Code and the Cybercrime Law should start delineating misinformation from disinformation which could potentially have two different consequences, where the former can have a more rehabilitative approach. The solutions to support the culture of factchecking in the country rely heavily on the policy's implementers, such as the national and local governments, journalist, and social media companies, to conscientiously work and ensure that the public has the appropriate guidance to fact-check the information they receive. This does not mean, however, that the community has a passive role - rather, they should be engaged by the said implementers to constantly practice factchecking, realizing that they empower themselves through such endeavor, and eventually demand accountability from individuals and institutions. All these efforts are aligned to sustain the culture of veritas in their communities.

\section{Conclusion}

When the COVID-19 pandemic struck, the Philippines struggled to respond quickly and misinformation became rampant. Although there are measures in place to provide a unified approach against the pandemic, such as the establishment of the IATF-EID, these did not directly address the infodemic that took place. Most responses against misinformation are reactive and reduced only to factchecking. A more proactive approach can be the constant production of understandable scientific information by an institutionalized, intersectoral science body which could not only streamline a centralized flow of information, but also provide readily available, reliable, and 
scientifically valid data. At the same time, current legal frameworks penalizing misinformation can adopt a rehabilitative approach and ensure the social media literacy of offenders through tests and seminars. The start of a culture of factchecking can be led by a partnership among the government, social media influencers, community leaders, media outlets, and the academe. Information becomes the thin line between life and death at a time of national and public health emergency. Therefore, the Philippines' fight against COVID-19 should not only be recognized as a struggle against the disease, but also a struggle against misinformation.

\section{Disclaimers}

This paper has been presented at the East Asian Medical Students' Conference 2021 on 8 January 2021.

\section{Sources of Support}

This white paper was self-funded. No other sources of support, financial or otherwise, were declared by the authors.

\section{Word Count}

Background $=267 ;$ Objectives $=51 ;$ Methods $=83 ;$ Problems $=917 ;$ Solutions $=$ 676; Conclusion $=194 ;$ Recommendations = 249; TOTAL = 2437

\section{References}

1. Bernadas, J. M. A. C., \& Ilagan, K. (2020). <? covid19?> Journalism, public health, and
COVID-19: some preliminary insights from the Philippines. Media International Australia, 177(1), 132-138.

2. Lwin M, Salmon C. A retrospective overview of health communication studies in Asia from 2000 to 2013. Asian Journal of Communication. 2015;25(1):1-13.

3. Bernhardt J. Communication at the Core of Effective Public Health. American Journal of Public Health. 2004;94(12):2051-2053.

4. Mheidly N, Fares J. Leveraging media and health communication strategies to overcome the COVID-19 infodemic. Journal of Public Health Policy. 2020;41(4):410-420.

5. An ad hoc WHO technical consultation managing the COVID-19 infodemic: call for action, 7-8 April 2020 [Internet]. World Health Organization [cited 19 November 2020]. Available from: https://www.who.int/docs/defaultsource/epi-win/final-recap-ofmeeting.pdf?sfvrsn=42f71c42_2\&download =true

6. Digital 2021: The Philippines DataReportal - Global Digital Insights [Internet]. DataReportal - Global Digital Insights. 2021 [cited 12 March 2021]. Available from: https://datareportal.com/reports/digital2021-philippines

7. David C, San Pascual M, Torres M. Reliance on Facebook for news and its influence on political engagement. PLOS ONE. 2019;14(3):e0212263.

8. Kajimoto M, Kwok Y, Chua Y, Labiste M. Information Disorder in Asia: Overview of Misinformation Ecosystem in Indonesia, Japan, and the Philippines. SSRN Electronic Journal. 2018;:29.

9. Agosto HG, Briones MV, Palatino MC. Correlates of health literacy among Filipinos aged 50-70 years old belonging to low-income families in a selected community. Acta Medica Philippina. 2018 May 31;52(3).

10. Camiling MK. eHealth Literacy of High School Students in the Philippines. IAFOR Journal of Education. 2019;7(2):69-87. 
11. Choi J. Reconstruction of Health-Seeking Behaviors. Qualitative Health Research. 2012;23(4):517-530.

12. Fuertes $M$, Jose $B$, Nem Singh $M$, Rubio $P$, de Guzman A. The moderating effects of information overload and academic procrastination on the information avoidance behavior among Filipino undergraduate thesis writers. Journal of Librarianship and Information Science. 2019;52(3):694-712.

13. Javier Jr. R, Tiongco M, Jabar, M. How health literate are the iGeneration Filipinos? Health Literacy Among Filipino Early Adolescents in Middle SChols. Asia-Pacific Social Science Review. 2019; 19(3): 16-29.

14. Sibal H, Foo S. A study on the information seeking behaviour of Singapore-based Filipino domestic workers. Information Development. 2016;32(5):1570-1584.

15. Factsheet no. 5: Understanding the infodemic and misinformation in the fight against COVID-19 [Internet]. Pan American Health Organization. 2020 [cited 19 November 2020]. Available from: https://iris.paho.org/bitstream/handle/1066 5.2/52052/Factsheet-

infodemic_eng.pdf?sequence=14\&isAllowe $d=y$

16. Wardle C, Derakhshan H. Information disorder: Toward an interdisciplinary framework for research and policy making [Internet]. Council of Europe Report, 27. 2017 [cited 19 November 2020]. Available from: https://rm.coe.int/informationdisorder-toward-an-interdisciplinaryframework-for-researc/168076277c

17. Ahmad A, Murad H. The Impact of Social Media on Panic During the COVID-19 Pandemic in Iraqi Kurdistan: Online Questionnaire Study. Journal of Medical Internet Research. 2020;22(5):e19556.

18. Nicomedes CJ, Avila RM. An analysis on the panic during COVID-19 pandemic through an online form. Journal of affective disorders. 2020 Nov 1;276:14-22.

19. Salari N, Hosseinian-Far A, Jalali R, VaisiRaygani A, Rasoulpoor S, Mohammadi M et al. Prevalence of stress, anxiety, depression among the general population during the
COVID-19 pandemic: a systematic review and meta-analysis. Globalization and Health. 2020;16(1).

20. CNN Philippines. FDA: Don't use chloroquine, hydroxychloroquine as COVID-19 preventive drugs. [Internet]. 2020 [cited 19 November 2020];. Available from: https://cnnphilippines.com/news/2020/3/2 4/FDA-chloroquine-hydroxychloroquinecoronavirusmedicine.html?fbclid=IWAR3sOrqAkOycbL WDwWGVev2Ey41fdTQ9RACpNRg1TSyoXX BUm-aZAFjqmpg

21. Montemayor M. DOH warns public vs 'tuob' [Internet]. Philippine News Agency. [Internet]. 2020 [cited 19 November 2020]. Available from: https://www.pna.gov.ph/articles/1107078

22. Rappler.com. Cebu province memo encourages employees to practice steam inhalation vs COVID-19. Rappler [Internet]. 2020 [cited 12 March 2021];: Available from: https://www.rappler.com/nation/cebuprovince-memo-steam-inhalationcoronavirus

23. Townlove H. There's a War Going on - Dr. Farrah and Her Garlic Vs Dr. Adam. [Internet]. 2020 [cited 12 March 2021]; Available from: https://townlove.medium.com/no-if-youhave-cancer-the-best-thing-for-you-is-notgarlic-127121fOe753

24. Rappler.com. FALSE: PH-developed COVID19 cure already approved. Rappler [Internet]. 2020 [cited 12 March 2021]; Available from: https://www.rappler.com/newsbreak/factcheck/philippines-developed-coronaviruscure-already-approved

25. Rappler.com. FALSE: 'Clean semen a cure for COVID-19'. Rappler [Internet]. 2020 [cited 12 March 2021];. Available from: https://www.rappler.com/newsbreak/factcheck/clean-semen-cure-coronavirus

26. Rodrigo Duterte: 'I'm not joking - clean masks with petrol' [Internet]. BBC News. BBC. 2020 [cited 12 March 2021]. Available from: https://www.bbc.com/news/worldasia-53605108 
27. Caguio R, Lomboy O. Understanding How Overseas Filipino Workers Engage on National Issues in Pinoy OFW Facebook Page. Procedia - Social and Behavioral Sciences. 2014;155:417-421.

28. Dayrit M, Mendoza R, Valenzuela S. The importance of effective risk communication and transparency: lessons from the dengue vaccine controversy in the Philippines. Journal of Public Health Policy. 2020;41(3):252-267.

29. Atoy M, Garcia F, Cadungog R, Cua J, Mangunay S, de Guzman A. Linking digital literacy and online information searching strategies of Philippine university students: The moderating role of mindfulness. Journal of Librarianship and Information Science. 2020;52(4):1015-1027.

30. Baterna H, Mina T, Rogayan D. Digital Literacy of STEM Senior High School Students: Basis for Enhancement Program. International Journal of Technology in Education. 2020;3(2):105.

31. Reese N. " Only if You Really, Really Need It": Social Rights Consciousness in the Philippines. ASEAS-Austrian Journal of South-East Asian Studies. 2017;10(1):83-99.

32. Kreuzer P. A Patron-Strongman who delivers: Explaining enduring public support for President Duterte in the Philippines. DEU; 2020.

33. David C, Tandoc E, Katigbak E. Organizational adaptations to social media: How social media news workers in the Philippines are embedded in newsrooms and influences on editorial practices. Newspaper Research Journal. 2019;40(3):329-345.

34. Brennen JS, Simon F, Howard PN, Nielsen RK. Types, sources, and claims of COVID-19 misinformation. Reuters Institute. $2020 \mathrm{Apr}$ 7;7:3-1.

35. Tangcharoensathien $\mathrm{V}$, Calleja $\mathrm{N}, \mathrm{Nguyen} \mathrm{T}$, Purnat T, D'Agostino M, Garcia-Saiso S et al. Framework for Managing the COVID-19 Infodemic: Methods and Results of an Online, Crowdsourced WHO Technical Consultation. Journal of Medical Internet Research. 2020;22(6):e19659.
36. Vallejo B, Ong R. Policy responses and government science advice for the COVID 19 pandemic in the Philippines: January to April 2020. Progress in Disaster Science. 2020;7:100115.

37. Executive Order No. 168, s. 2014. Official Gazette of the Republic of the Philippines; 2014.

38. Rasi P, Vuojärvi H, Rivinen S. Promoting Media Literacy Among Older People: A Systematic Review. Adult Education Quarterly. 2020;71(1):37-54.

39. Guess A, Nagler J, Tucker J. Less than you think: Prevalence and predictors of fake news dissemination on Facebook. Science Advances. 2019;5(1):eaau4586.

40. Rosen G. An Update on Our Work to Keep People Informed and Limit Misinformation About COVID-19 - About Facebook [Internet]. Facebook. 2020 [cited 19 November 2020]. Available from: https://about.fb.com/news/2020/04/covid19-misinfo-update/

41. Celliers M, Hattingh M. A Systematic Review on Fake News Themes Reported in Literature. Lecture Notes in Computer Science. 2020;:223-234.

42. Pazzanese C. Social media used to spread, create COVID-19 falsehoods [Internet]. Harvard Gazette. 2020 [cited 16 February 2021]. Available from: https://news.harvard.edu/gazette/story/202 0/05/social-media-used-to-spread-createcovid-19-falsehoods/

43. Republic Act No. 10175. Official Gazette of the Republic of the Philippines; 2012.

44. Radu R. Fighting the 'Infodemic': Legal Responses to COVID-19 Disinformation. Social Media + Society. 2020;6(3):205630512094819.

45. Republic Act No. 11469. Official Gazette of the Republic of the Philippines; 2020.

46. Biong I. DJ Loonyo gets flak for erroneous mass testing statement, apologizes for 'wrong use of terminology'. Inquirer [Internet]. 2020 [cited 19 November 2020]; Available from: https://entertainment.inquirer.net/377744/ 
dj-loonyo-gets-flak-for-erroneous-masstesting-statements-apologizes-for-wronguse-of-terminology

47. Buan L. NBI probes Mocha Uson for fake news over false PPE post. Rappler [Internet]. 2020 [cited 19 November 2020]; Available from: https://www.rappler.com/nation/nbiprobes-mocha-uson-fake-news-false-ppespost

48. Chavez C. DILG warns public against nCoV fake news infographic. Manila Bulletin [Internet]. 2020 [cited 19 November 2020]; Available from: https://mb.com.ph/2020/02/11/dilg-warnspublic-against-ncov-fake-newsinfographic/

49. Esguerra D.J No joke: Duterte says on suggestion to use 'gaas' as disinfectant. Inquirer [Internet]. 2020 [cited 19 November 2020];. Available from: https://newsinfo.inquirer.net/1314867/nojoke-duterte-says-on-suggestion-to-usegaas-as-disinfectant

50. Mayol AV. Provincial gov't: Make time for 'tuob'. Inquirer [Internet]. 2020 [cited 19 November 2020];. Available from: https://newsinfo.inquirer.net/1296441/provi ncial- govt-memo-make-time-for-tuob.

51. Mayol AV. Cebu City spends P2.5 million for 'tuob' kits. Inquirer [Internet]. 2020 [cited 19 November 2020];. Available from: https://newsinfo.inquirer.net/1305865/cebu -city- spends-p-2-5m-for-tuob-kits.

52. Press Freedom Further Restricted Amid Covid-19 Pandemic [Internet]. Philippine Center for Investigative Journalism. 2020 [cited 19 November 2020]. Available from: https://pcij.org/article/4009/state-ofmedia-freedom-in-ph-2

53. Act No. 3815, s. 1930 An Act Revising the Penal Code and Other Penal Laws. Official Gazette of the Republic of the Philippines; 1930.

54. Esmaquel II P.R. Filipino chemists factcheck Duterte: Gasoline is not a disinfectant. Rappler [Internet]. 2020 [cited 19 November 2020]; Available from: https://www.rappler.com/nation/nbi- probes-mocha-uson-fake-news-false-ppespost

55. Municipal Ordinance No 2020-201. General Mariano Alvarez, Cavite, Philippines; 2020.

56. Cabañes J, Anderson C, Ong J. Fake News and Scandal. In: Tumber $\mathrm{H}$, Waisbord S, ed. by. The Routledge Companion to Media and Scandal [Internet]. London: Routledge; 2019 [cited 19 November 2020]. Available from: https://scholarworks.umass.edu/communic ation_faculty_pubs/88/

57. Hall $P$, Land $H$, Parker R, Web A. Change, choice and conflict in social policy. London: Heinemann; 1975.

58. Carrier J, Hall P, Land H, Parker R, Webb A, Glennerster $\mathrm{H}$. Change, Choice and Conflict in Social Policy. The British Journal of Sociology. 1977;28(4):520. 